\title{
INTEGRATED NMR-BASED METABONOMIC INVESTIGATION OF EARLY METABOLIC EFFECTS OF ETHYLENE GLYCOL MONOMETHYL ETHER (EGME) ON MALE REPRODUCTIVE ORGANS IN RATS
}

\author{
Toshinori YAMAMOTO ${ }^{1,2}$, Ikuo HORII ${ }^{1,2}$ and Takemi YOSHIDA ${ }^{2}$ \\ ${ }^{1}$ Drug Safety Research \& Development, Pfizer Global Research \& Development, Nagoya Laboratories, Pfizer Inc, \\ 5-2 Taketoyo, Aichi 470-2393, Japan \\ ${ }^{2}$ Department of Biochemical Toxicology, School of Pharmaceutical Sciences, Showa University, \\ 1-5-8 Hatanodai, Shinagawa-ku, Tokyo 142-8555, Japan
}

(Received September 21, 2007; Accepted September 30, 2007)

\begin{abstract}
High-resolution Magic Angle Spinning (Hr-MAS) ${ }^{1} \mathrm{H}-\mathrm{NMR}$ spectroscopy was used to analyze intact testicular tissues ex vivo and to investigate the toxicological effects of ethylene glycol monomethyl ether (EGME), a well-known spermatocytes toxicant, on male reproductive organs by NMRbased metabonomic analysis. Especially, we reported the first Hr-MAS ${ }^{1} \mathrm{H}-\mathrm{NMR}$ spectra of epididymis. Sexually matured male rats were treated with 50 and 2,000 $\mathrm{mg} / \mathrm{kg}$ EGME, and body weight, reproductive organs weight, histopathology and plasma biochemistry were examined at 6 and $24 \mathrm{hr}$ after administration. Two multivariate statistical methods, namely, unsupervised PCA and supervised PLS-DA, indicated that the balance of endogenous metabolites was perturbed in both reproductive organs and biofluids. In the testes, lactate, creatine and glutathione were mainly affected by EGME treatment. In urine and plasma, altered excretions of the TCA cycle intermediates (2-oxoglutarate, citrate and succinate) and the ketonebodies (acetoacetate and $\beta$-hydroxybutyrate) were also observed. The finding in current integrated metabonomic analysis of both intact tissues and biofluids suggested that EGME-induced testicular toxicity was attributed to perturbation of the energy supply processes, suppression of the TCA cycle, or oxidative stress. Furthermore, Hr-MAS ${ }^{1} \mathrm{H}-\mathrm{NMR}$ proved useful to investigate the molecular snapshot of biological tissues and the mechanism of toxicity.
\end{abstract}

KEY WORDS: Metabonomics, Hr-MAS NMR, Ethylene glycol monomethyl ether, Rat, Testicular toxicity

\section{INTRODUCTION}

Ethylene glycol monomethyl ether (EGME) is widely used as a solvent for varnishes, dyes, paints and printing inks. In the industry, EGME is extensively utilized in the manufacture of photographic film and as an anti-freeze in jet-fuels. EGME is readily absorbed, either percutaneously or by inhalation, into the human body due to its volatile nature. Hence, undesirable adverse effects on several organs have been reported. Male reproductive toxicity due to EGME, one of the critical adverse events, was described more than 60 years ago (Wiley et al., 1936). Studies in laboratory animals showed that EGME induced testicular atrophy and impaired infertility (Chapin et al., 1984; Anderson et al., 1987; Foster et al., 1983, 1984). In the testes, the primary and pachytene spermatocytes were known as targets of EGME, while early and late stage spermatids, and Sertoli cells did not appear affected (Chapin and Lamb, 1984).

Several "omics" investigations have been conducted to elucidate the molecular basis of testicular damage induced by EGME. Transcriptomic analysis revealed that several genes, which had important roles in spermatogenesis, were differentially expressed in testes after EGME treatment (Wang and Chapin, 2000; Fukushima et al., 2005). Syed and Hecht (1998) also demonstrated that EGME induced changes in gene

Correspondence: Toshinori YAMAMOTO (E-mail: Toshinori.Yamamoto@pfizer.com) 


\section{T. YAMAMOTO et al.}

expression in Sertoli cells as well as in spermatocytes. Interestingly, they detected up-regulation of the gene coding oxidative stress-responsive protein in Sertoli cells, despite these cells not being considered a target of EGME. Although there were few reports regarding global protein expression (proteomics), spermatogenesis-related and oxidative stress-inducible proteins were found to be affected by several reproductive toxicants, including EGME (Yamamoto et al., 2005). In this context, studies on the content of endogenous metabolites and their alterations will further clarify biological processes.

Nuclear magnetic resonance (NMR)-based metabonomics is a relatively new technique used to comprehensively investigate biological processes, as a next generation of 'omics' technology (Lindon et al., 2000). A considerable benefit of metabonomic analysis is that the findings directly link to the responses seen in vivo. Metabonomics is usually conducted on biofluids, mainly urine, plasma and serum. Therefore, one of the key advantages of metabonomics is that samples can be obtained non-invasively and the time course of alterations can be monitored within individual animals. In contrast, it is often difficult to identify the affected organ because analytes are either urine or plasma. High-resolution Magic Angle Spinning (HrMAS) is one of the "solid-state" ${ }^{1} \mathrm{H}-\mathrm{NMR}$ techniques, which enables direct monitoring of the metabolic state of various intact biological tissues. Hr-MAS ${ }^{1} \mathrm{H}-\mathrm{NMR}$ spectroscopy has recently been successfully used on several intact tissues in the following studies: liver (Waters et al., 2001; Coen et al., 2003; Leliott et al., 2005); kidney (Garrod et al., 1999, 2001); gut (Martin et al., 2007); lung (Azmi et al., 2005); lens (Tessem et al., 2006); gastric mucosa (Schenetti et al., 2006) and brain (Cheng et al., 1997). Integrated metabonomic analyses by both Hr-MAS ${ }^{1} \mathrm{H}-\mathrm{NMR}$ of tissues and "liquid-state" ${ }^{1} \mathrm{H}$-NMR of biofluids will provide novel knowledge related to biological and toxicological responses in the body.

The present study was aimed to monitor the details of metabolic perturbation, when testes were damaged by a single dose of EGME. Using NMRbased metabonomic analyses, we investigated the effects of EGME on endogenous metabolites in reproductive organs and biofluids. In summary, we successfully detected several changes in endogenous metabolites in testes, epididymides, urine and plasma. The findings suggested that EGME-induced testicular toxicity resulted from either alterations of the energy metabolism, TCA cycle, or oxidative stress. Besides, integrated evaluation of endogenous metabolites in tissues and biofluids revealed by "solid-state" and "liquid-state" NMR-based metabonomics proved useful to evaluate mechanisms of toxicity.

\section{MATERIALS AND METHODS}

\section{Animals and treatment}

The present study was conducted under the approval of the Animal Ethics Committee (Institute of Animal Care \& Use Committee of Pfizer Inc.). Twelveweek-old Sprague-Dawley male rats [Crj:CD(SD)IGS] were purchased from Charles-River Laboratories Japan, Inc. (Yokohama, Kanagawa, Japan). The animals were acclimated to our laboratory for 1 week, and then randomly assigned to each treatment group by body weight. The animals were housed individually in metabolic cages and maintained under controlled room temperature $\left(21-25^{\circ} \mathrm{C}\right)$ and lighting (12-hr light and dark cycle). The animals were given access to municipal drinking water and an animal diet ad libitum. In the present study, ethylene glycol monomethyl ether (EGME) (Sigma, St. Louis, MO, USA) was used as the male reproductive toxicant. Individual animals were administered EGME by oral gavage at doses of 50 (low-dose) and 2,000 mg/kg (high-dose) using a Teflon sonde. The dosing solution of EGME was prepared by dilution with distilled water. The animals assigned to the control group were given distilled water. Five animals each were assigned to the control and treatments groups. Six and $24 \mathrm{hr}$ after the administration, the control and EGME-treated animals were euthanized under $\mathrm{CO}_{2}$ inhalation, and then blood and the reproductive organs were removed. The body and reproductive organs weight was recorded.

\section{Sample collection}

As for the $24 \mathrm{hr}$ treatment group, urine was collected into conical tubes containing $1 \%(\mathrm{w} / \mathrm{v})$ sodium azide (Wako Pure Chemicals, Osaka, Japan) from animals housed in metabolic cages. The tubes were maintained under cold conditions during the collection of urine. The periods for sampling of urine were as follows: -24 to $-16 \mathrm{hr},-16$ to $0 \mathrm{hr}$ (pre-dose), 0 to $8 \mathrm{hr}$ and 8 to $24 \mathrm{hr}$ (post-dose). Blood and reproductive organs were collected at necropsy 6 and $24 \mathrm{hr}$ after the administration. Plasma was immediately separated by centrifugation at $3,000 \mathrm{rpm}$ for $10 \mathrm{~min}$ at $4^{\circ} \mathrm{C}$. The left testis of each animal was fixed in $4 \%$ paraformaldehyde for histopathological examination. The right testis and epididymis were immediately frozen in liquid 
Metabonomic investigation of testicular toxicity induced by EGME.

nitrogen. These samples were stored below $-80^{\circ} \mathrm{C}$ for subsequent clinicopathological and metabonomic analysis.

\section{Plasma biochemistry}

The following parameters were measured: alanine aminotransferase (ALT), aspartate aminotransferase (AST), alkaline phosphatase (ALP), $\gamma$-glutamyl transpeptidase (GGT), total bilirubin (TB), blood urea nitrogen (BUN), creatinine (CREA), total cholesterol (T-CHOL), and total protein (TPR). The data were obtained using the clinical automatic analyzer H-7070 (Hitachi, Ltd., Tokyo, Japan).

\section{Testes histopathology}

One testis from each animal was examined. The fixed testes were embedded in paraffin and blocks were prepared. Testicular sections were obtained from each testis at $5 \mu \mathrm{m}$ thickness, then stained with hematoxylin and eosin (Wako Pure Chemicals), and examined by light microscopy.

\section{Hr-MAS ${ }^{1} \mathrm{H}$-NMR spectroscopy of reproductive organs}

Reproductive organs, testes and epididymides, collected at the necropsy at $24 \mathrm{hr}$ after EGME administration were subjected to "solid-state" Hr-MAS ${ }^{1} \mathrm{H}$ NMR spectroscopic analysis. Samples of reproductive organs (10 to $20 \mathrm{mg}$ ) were placed in $4 \mathrm{~mm}$ outer diameter zirconia rotors (Bruker Biospin $\mathrm{GmbH}$, Rheinstetten, Germany), and then $50 \mu \mathrm{L}$ of $\mathrm{D}_{2} \mathrm{O}$ (ISOTEC Inc., Miamisburg, $\mathrm{OH}$, USA) containing $1 \mathrm{mM}$ sodium 3-trimethylsilyl-(2,2,3,3- $\left.{ }^{2} \mathrm{H}_{4}\right)$-1-propionate $\left(\mathrm{TSP}-\mathrm{d}_{4}\right.$, ISOTEC Inc.) was added. TSP and $\mathrm{D}_{2} \mathrm{O}$ provided the chemical shift references $\left(\delta_{\mathrm{H}} 0.0\right)$ and a field-frequency lock signal for the NMR spectrometer in acquisition of free induction decay (FID), respectively. HrMAS ${ }^{1} \mathrm{H}-\mathrm{NMR}$ measurements were made on a Bruker DRX600 NMR spectrometer (Bruker Biospin GmbH) operating at $600.13 \mathrm{MHz}{ }^{1} \mathrm{H}$ frequency at a MAS spin rate of $5,000 \mathrm{~Hz}$. Hr-MAS spectra were acquired at ambient probe temperature $(300 \mathrm{~K})$. The one-dimensional $\mathrm{T}_{2}$-edited Carr-Purcell-Meiboom-Gill (CPMG) spin-echo pulse sequence [RD (relaxation delay) $-\pi / 2 \mathrm{x}^{-}$ $\left(\tau-\pi_{\mathrm{y}}-\tau\right)_{\mathrm{n}}$-acquisition] with standard presaturation of the water resonance was applied to the measurements. Here, $\tau$ and $n$ represent the refocusing delay time and number of cycles, respectively. These parameters were set to $1 \mathrm{~ms}$ and 30 cycles, respectively; thus, the total spin-echo time $(2 \mathrm{n} \tau)$ was calculated to be $60 \mathrm{~ms}$.

\section{${ }^{1}$ H-NMR spectroscopy of biofluids}

Urine and plasma were subjected to "liquidstate" ${ }^{1} \mathrm{H}-\mathrm{NMR}$ spectroscopy. Aliquots of urine were added to half volume of the buffer $(0.2 \mathrm{M}$ sodium phosphate buffer $\left(\mathrm{H}_{2} \mathrm{O} / \mathrm{D}_{2} \mathrm{O} ; 90 / 10\right)$ containing $1 \mathrm{mM}$ TSP$\mathrm{d}_{4}$ and $3 \mathrm{mM}$ sodium azide) to stabilize the urine $\mathrm{pH}$. On the other hand, aliquots of plasma were mixed with two volumes of $0.9 \%(\mathrm{w} / \mathrm{v}) \mathrm{NaCl}$ (Wako Pure Chemicals) in $\mathrm{H}_{2} \mathrm{O} / \mathrm{D}_{2} \mathrm{O}(90 / 10)$ solution. After vigorously mixing both samples, they were allowed to stand for a few minutes and then centrifuged at 10,000 rpm for 5 min to remove insoluble materials and visible particles. One-dimensional ${ }^{1} \mathrm{H}-\mathrm{NMR}$ spectra of urine and plasma were acquired using the Bruker DRX600 NMR spectrometer (Bruker Biospin $\mathrm{GmbH}$ ) at $600.13 \mathrm{MHz}{ }^{1} \mathrm{H}$ observation frequency at ambient probe temperature (300 K). Standard presaturation pulse sequence for water signal suppression was used; namely, nuclear Overhauser effect correlated spectroscopy (NOESY)presaturation for urine samples and CPMG-presaturation for plasma samples. Chemical shifts were referenced to TSP at $0 \mathrm{ppm}$ and the glucose doublet signal at $5.23 \mathrm{ppm}$ for urine and plasma spectra, respectively.

\section{NMR spectral data processing}

Using XWIN-NMR software (Ver. 2.5, Bruker Biospin $\mathrm{GmbH}$ ), Fourier transformation was made for all FIDs acquired, and then ${ }^{1} \mathrm{H}-\mathrm{NMR}$ spectra were manually corrected for phase and baseline distortions. The appropriate spectral region (reproductive organs: $\delta$ $0.2-9.0$; urine: $\delta 0.2-10.0$; plasma: $\delta 0.2-6.0$ ) was integrated into buckets $0.04 \mathrm{ppm}$ wide ("bins") using AMIX program (ver. 3.6.8, Bruker Biospin $\mathrm{GmbH}$ ) to reduce data complexity of the spectra. The region corresponding to water resonance in the spectrum (reproductive organs: $\delta$ 4.70-5.10, urine: $\delta$ 4.50-5.40, plasma: $\delta 4.66-5.06)$ was removed from the analysis. In addition, the region of urea resonance $(\delta 5.40-6.00)$ was also set to zero integral value for only urine spectra. To avoid including xenobiotic-related metabolites in the analysis, the dosed compound related resonances were also omitted for urine and plasma spectra. The integration values of the remaining spectral region were divided by the total intensity to normalize the value (global normalization) before pattern recognition analysis.

\section{Multivariate statistical analysis in metabonomic analysis}

The data sets of "bins" NMR spectra were imported into the SIMCA-P software package (ver. 


\section{T. YAMAMOTO et al.}

11.5, Umetrics AB, Umea, Sweden) for multivariate statistical analyses as pattern recognition. To evaluate the changes in patterns derived from the differences in the content of endogenous metabolites, unsupervised principal component analysis (PCA) and supervised projections to latent structures by means of partial least squares-discriminant analysis (PLS-DA) were applied to the analysis of all spectra. Prior to data analysis, the variables were mean-centered and Pareto scaled, that is, each variable was weighed by the square root of its standard deviation. At first, PCA using the entire data set was performed to indicate trends of group characteristics and time course, outliers, and any other systemic pattern within the analysis. Next, PLSDA was conducted to focus on the classification and discrimination between the treatments classes (e.g. control versus treatment). PLS-DA was directed at determining bins that indicated meaningful endogenous metabolites, in the data that correlated with these known classes.

\section{Statistical analysis}

Body weight, reproductive organs weight and parameters of plasma biochemistry were expressed as the mean \pm SD of 5 rats, and statistical significance was determined by Dunnett's multiple comparison procedure (Gad and Weil, 1994). A probability of less than $5 \%$ was considered to be statistically significant.

\section{RESULTS}

\section{Body and reproductive organs weight}

Table 1 shows the body weight and reproductive organs weight at 6 and $24 \mathrm{hr}$ after treatment. There were no remarkable changes in body and reproductive organs weight at $6 \mathrm{hr}$ after the administration of EGME. At $24 \mathrm{hr}$, significant decreases in body weight were observed only in the high-dose group. Regarding reproductive organs, the weight of testes from rats administered the high-dose EGME tended to decrease, but the difference with the control group was not statistically significant.

\section{Plasma biochemistry}

Except for ALT, ALP and BUN in the high-dose group, most clinicopathological parameters did not change remarkably (Table 2). An elevation of BUN was observed in the high-dose at $24 \mathrm{hr}$ after administration, whereas no change in plasma creatinine levels was detected. In addition, no change in urinary protein levels was observed at this time point compared with the levels in the control group (data not shown). Therefore, the slight elevation of BUN might not have been due to the kidney dysfunction.

\section{Testes histopathology}

Testes were histopatologically examined at 6 and $24 \mathrm{hr}$ after the administration of EGME (Fig. 1). Histopathological changes were detected only in the highdose group. Slight degeneration was observed in some pachytene spermatocytes at $6 \mathrm{hr}$ (data not shown). At $24 \mathrm{hr}$, degenerative changes were observed in spermatocytes. On the other hand, there were no remarkable histopathological changes related to the administration of EGME at low dose.

\section{Hr-MAS ${ }^{1} \mathrm{H}$-NMR spectra of reproductive organs}

Hr-MAS ${ }^{1} \mathrm{H}-\mathrm{NMR}$ spectroscopic analysis provided the snapshots of metabolic profiles in reproductive organs excised from the same individual rat. Fig. 2 shows the typical spectra of a testis, and caput and cauda regions of the epididymis. The Hr-MAS ${ }^{1} \mathrm{H}-$ NMR spectrum of testis was characterized by high contents of creatine and phosphatidylcholine (Fig. 2A). On the other hand, the epididymis showed different profiles of endogenous metabolites in comparison with testis. The spectra (Figs. 2B and 2C) showed that endogenous metabolites in the epididymis were altered

Table 1. Body weight and reproductive organs weight of male rats at 6 and $24 \mathrm{hr}$ after the administration of EGME.

\begin{tabular}{|c|c|c|c|c|c|c|}
\hline & \multicolumn{3}{|c|}{$6 \mathrm{hr}$} & \multicolumn{3}{|c|}{$24 \mathrm{hr}$} \\
\hline & \multirow{2}{*}{ Control } & \multicolumn{2}{|c|}{ EGME } & \multirow{2}{*}{ Control } & \multicolumn{2}{|c|}{ EGME } \\
\hline & & $50 \mathrm{mg} / \mathrm{kg}$ & $2,000 \mathrm{mg} / \mathrm{kg}$ & & $50 \mathrm{mg} / \mathrm{kg}$ & $2,000 \mathrm{mg} / \mathrm{kg}$ \\
\hline Body weight (g) & $392.6 \pm 18.3$ & $396.8 \pm 17.1$ & $395.6 \pm 24.2$ & $410.5 \pm 21.2$ & $397.0 \pm 25.3$ & $373.3 \pm 11.4^{*}$ \\
\hline Testis (g) & $3.167 \pm 0.119$ & $2.957 \pm 0.278$ & $3.018 \pm 0.203$ & $3.065 \pm 0.291$ & $3.013 \pm 0.282$ & $2.912 \pm 0.077$ \\
\hline Epididymis (g) & $1.148 \pm 0.070$ & $1.157 \pm 0.071$ & $1.152 \pm 0.056$ & $1.053 \pm 0.061$ & $1.145 \pm 0.130$ & $1.140 \pm 0.092$ \\
\hline
\end{tabular}

Each value represents the mean \pm S.D. of 5 rats.

[*] indicates statistically significant difference from the control group ( $\mathrm{p}<0.05$, Dunnett's multiple comparison). 
Metabonomic investigation of testicular toxicity induced by EGME.

Table 2. Clinical pathology of plasma from male rats administered a single dose of EGME at 6 and $24 \mathrm{hr}$ after the administration.

\begin{tabular}{|c|c|c|c|c|c|c|}
\hline & \multicolumn{3}{|c|}{$6 \mathrm{hr}$} & \multicolumn{3}{|c|}{$24 \mathrm{hr}$} \\
\hline & \multirow{2}{*}{ Control } & \multicolumn{2}{|c|}{ EGME } & \multirow{2}{*}{ Control } & \multicolumn{2}{|c|}{ EGME } \\
\hline & & $50 \mathrm{mg} / \mathrm{kg}$ & $2,000 \mathrm{mg} / \mathrm{kg}$ & & $50 \mathrm{mg} / \mathrm{kg}$ & $2,000 \mathrm{mg} / \mathrm{kg}$ \\
\hline GGT (U/L) & $0.6 \pm 0.5$ & $0.6 \pm \quad 0.5$ & $0.4 \pm \quad 0.5$ & $1.0 \pm 0.0$ & $1.0 \pm 0.0$ & $0.6 \pm 0.5$ \\
\hline AST (U/L) & $76.6 \pm 10.3$ & $75.2 \pm 5.0$ & $81.4 \pm 9.4$ & $84.6 \pm 14.0$ & $92.0 \pm 25.9$ & $126.2 \pm 54.2$ \\
\hline ALT (U/L) & $35.6 \pm 3.6$ & $39.4 \pm \quad 1.8$ & $43.4 \pm \quad 4.9 *$ & $43.6 \pm 9.0$ & $35.2 \pm 9.7$ & $47.0 \pm 21.2$ \\
\hline ALP (U/L) & $420.2 \pm 88.2$ & $468.2 \pm 128.2$ & $468.6 \pm 100.0$ & $492.2 \pm 80.4$ & $379.4 \pm 26.1 *$ & $295.8 \pm 32.2 *$ \\
\hline TB (mg/dL) & $0.1 \pm 0.0$ & $0.1 \pm$ & $0.1 \pm \quad 0.0$ & $0.1 \pm 0.0$ & $0.1 \pm 0.0$ & $0.1 \pm 0.0$ \\
\hline BUN (mg/dL) & $12.8 \pm 2.5$ & $12.8 \pm$ & $14.8 \pm$ & $13.8 \pm 1.8$ & $14.0 \pm 1.6$ & $22.4 \pm 3.7^{*}$ \\
\hline CREA (mg/dL) & $0.3 \pm 0.1$ & $0.2 \pm$ & $0.0 \pm$ & $0.3 \pm 0.1$ & $0.3 \pm 0.0$ & $0.3 \pm 0.1$ \\
\hline CHOL (mg/dL) & $58.0 \pm 10.9$ & $65.8 \pm$ & $74.2 \pm 13.7$ & $69.2 \pm 12.6$ & $65.6 \pm 9.2$ & $50.2 \pm 10.0$ \\
\hline TPR (g/dL) & $5.8 \pm 0.3$ & $6.1 \pm$ & $6.7 \pm \quad 0.2$ & $6.0 \pm 0.4$ & $6.1 \pm 0.4$ & $6.8 \pm 0.3$ \\
\hline
\end{tabular}

Each value represents the mean \pm standard deviation (SD) of 5 rats.

[*] indicates statistically significant difference from the control group ( $\mathrm{p}<0.05$, Dunnett's multiple comparison).
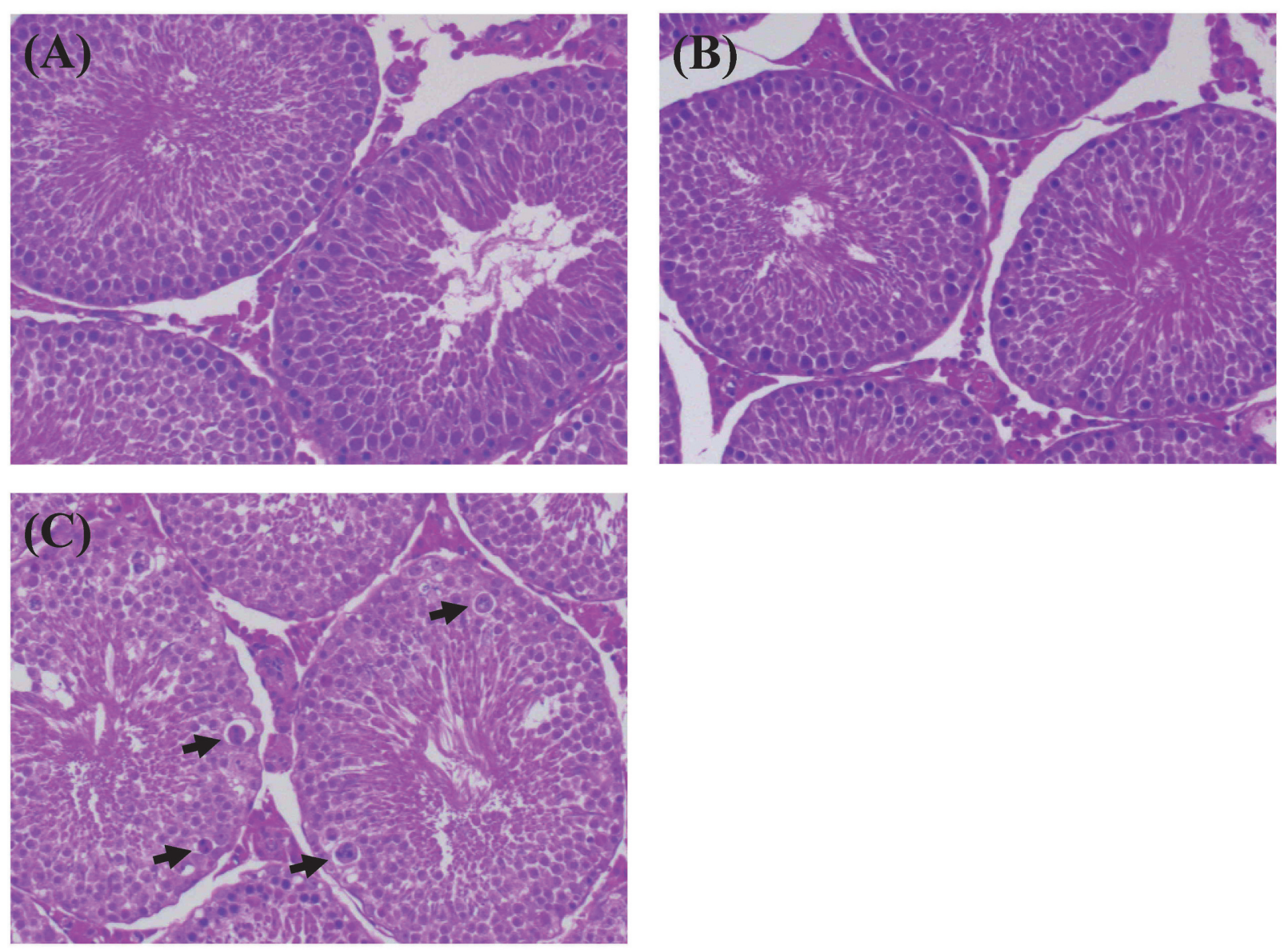

Fig. 1. Photomicrographs of cross-sections of a testis stained with hematoxylin and eosin. The pictures (A), (B) and (C) represent control, EGME low-dose $(50 \mathrm{mg} / \mathrm{kg})$ and high-dose $(2,000 \mathrm{mg} / \mathrm{kg})$ groups at $24 \mathrm{hr}$ after the administration, respectively. Degenerative changes of spermatocytes were observed with the high dose of EGME (black arrows). 


\section{T. YAMAMOTO et al.}

along the length of the epididymis. The caput region of the epididymis contained a large amount of lipids, such as triglycerides and fatty acids (Fig. 2B), while the cauda region of the epididymis had a high content of phosphocholine and glycerophosphocholine (Fig. 2C).

\section{Metabonomic analysis of reproductive organs}

We investigated the effect of EGME on reproduc- tive organs using Hr-MAS ${ }^{1} \mathrm{H}-\mathrm{NMR}$ spectrometric analysis. Fig. 3 shows the changes of metabolic profiles affected by EGME treatment both in testis and caput epididymis. The initial PCA analysis of the HrMAS ${ }^{1} \mathrm{H}-\mathrm{NMR}$ spectra of reproductive organs showed the effects of EGME on each reproductive organ. The PCA scores plot of testis spectra revealed apparent differences among the three groups of treatment, indicat-

(A)

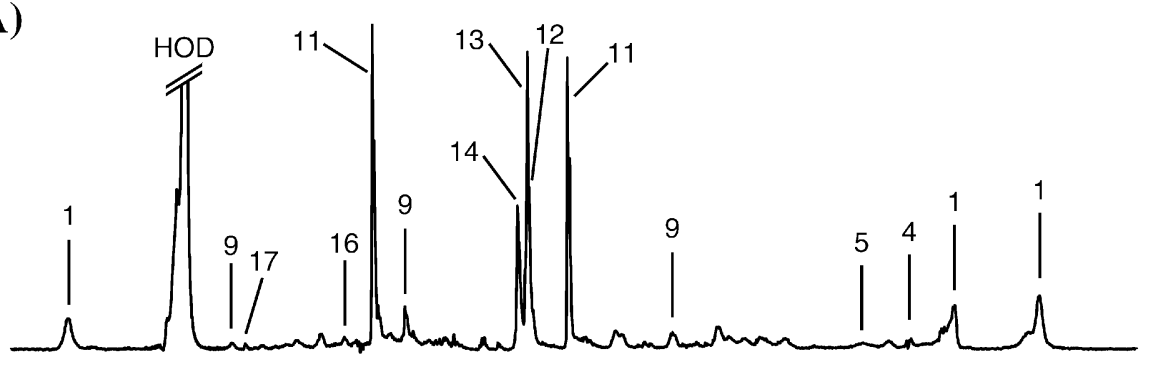

(B)

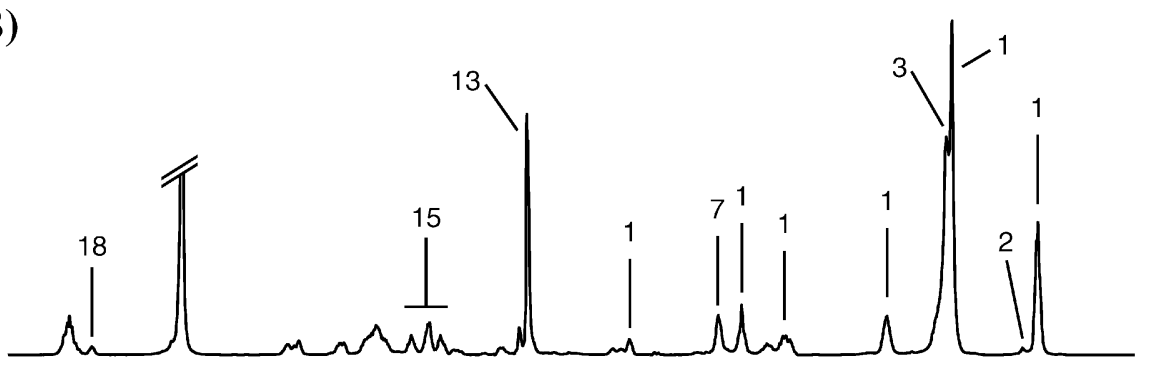

(C)

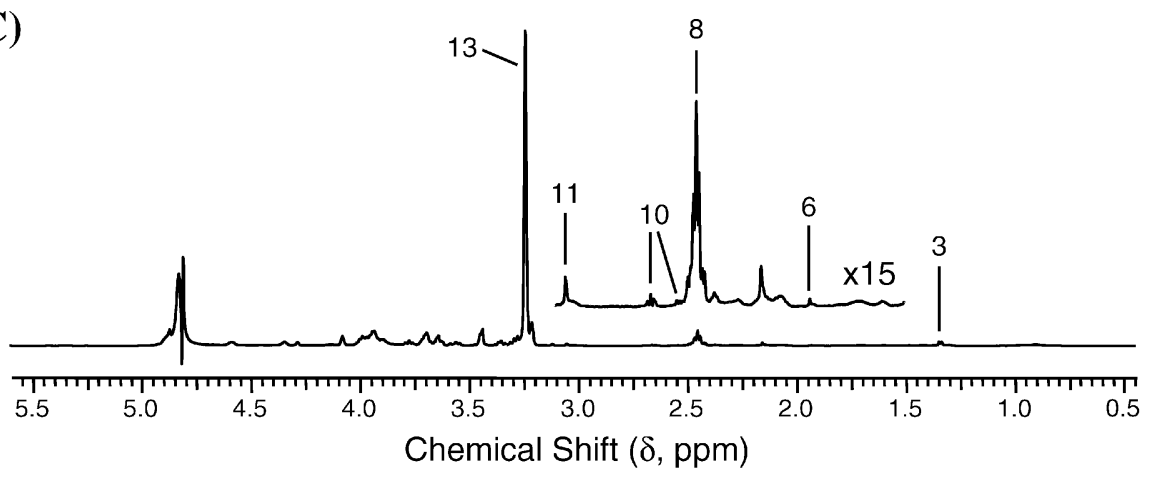

Fig. 2. Typical one-dimensional Hr-MAS ${ }^{1} \mathrm{H}-\mathrm{NMR}$ spectra $(600 \mathrm{MHz})$ of intact reproductive tissues obtained from a control rat: testis (A), caput region of epididymis (B), and cauda region of epididymis $(\mathrm{C})$. These reproductive tissues were obtained from the same animal. Spectra were acquired using a CPMG-presaturation pulse sequence at $5,000 \mathrm{~Hz}$ spinning rate (total spin-echo relaxation delay: $60 \mathrm{~ms}$ ).

Keys: 1, lipid (triglycerides, fatty acids); 2, leucine, isoleucine; 3, lactate; 4, alanine; 5, lysine; 6 , acetate; 7, glutamate; 8 , glutamine; 9, glutathione; 10, citrate; 11, creatine; 12 , choline; 13 , phosphocholine, glycerophosphocholine; 14, phosphatidylcholine; 15, myoinositol; 16, creatinine; 17, $N$-methyl nicotinate; $18, \alpha$-glucose. 
Metabonomic investigation of testicular toxicity induced by EGME.

ing that EGME-related changes occurred in the testes at the level of endogenous metabolites (Fig. 4a). Regarding the caput region of the epididymis, clusters of the calculated PCA scores in the treated groups were relatively separated from those in the control group (Fig. 4b). The PCA analysis of the cauda epididymis did not show treatment-related alterations at the level of endogenous metabolites (Fig. 4c).

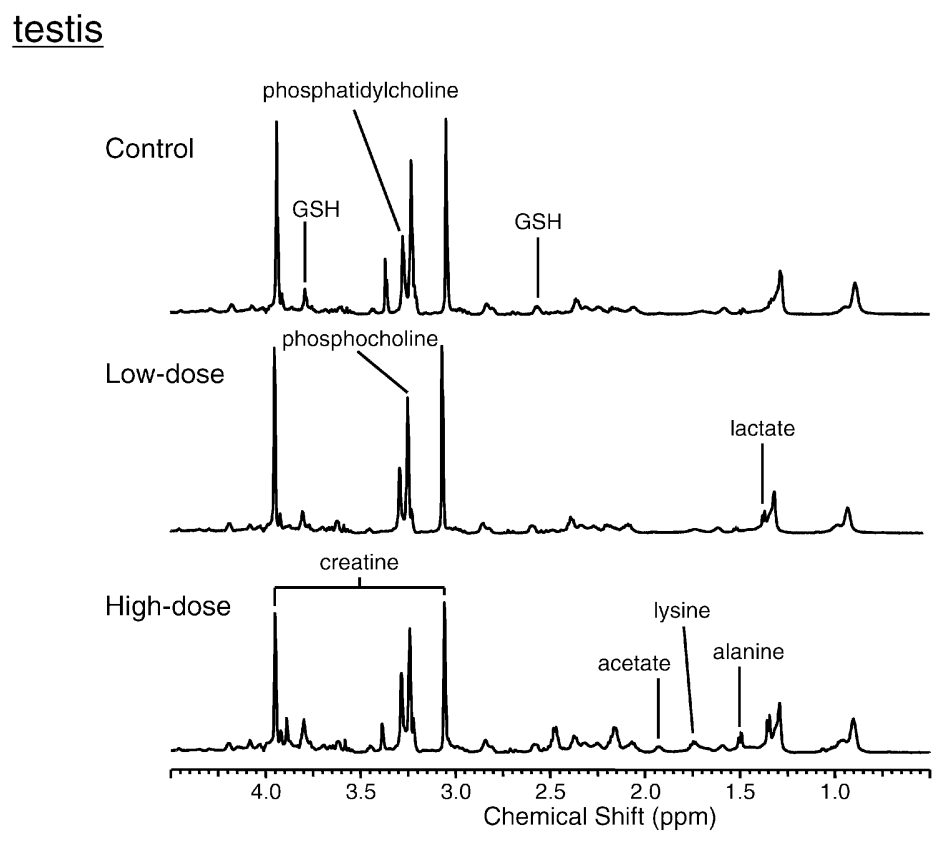

\section{caput epididymis}

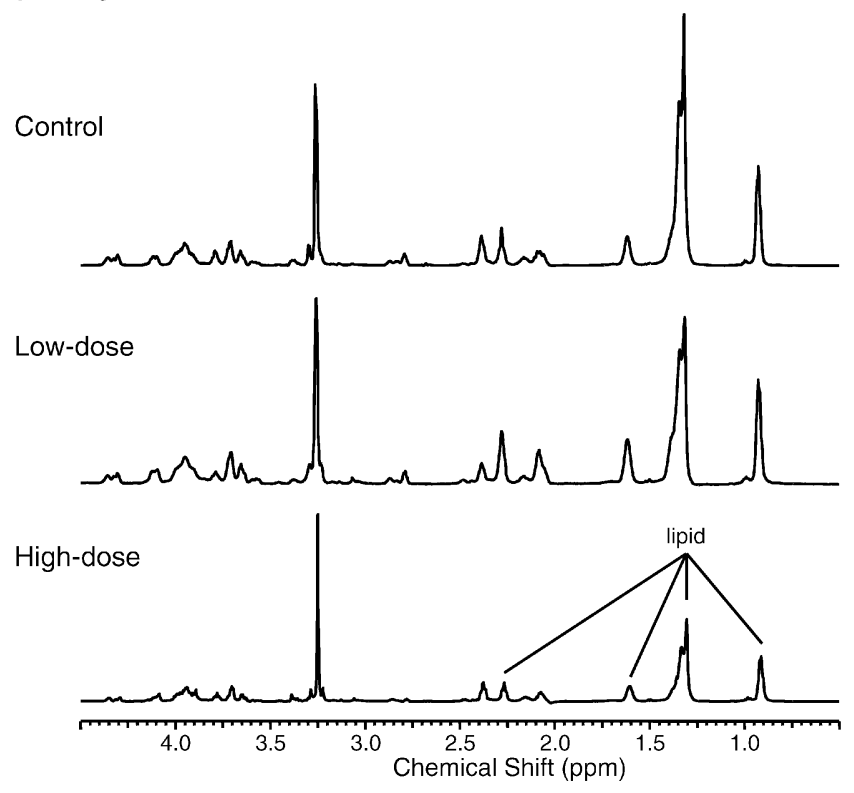

Fig. 3. Series of $600 \mathrm{MHz}$ Hr-MAS ${ }^{1} \mathrm{H}-\mathrm{NMR}$ spectra $(\delta$ 0.5-4.5) of testis and caput epididymis from control rat and rats dosed with EGME (low- and high-dose) obtained at $24 \mathrm{hr}$ post dose. 
(a)

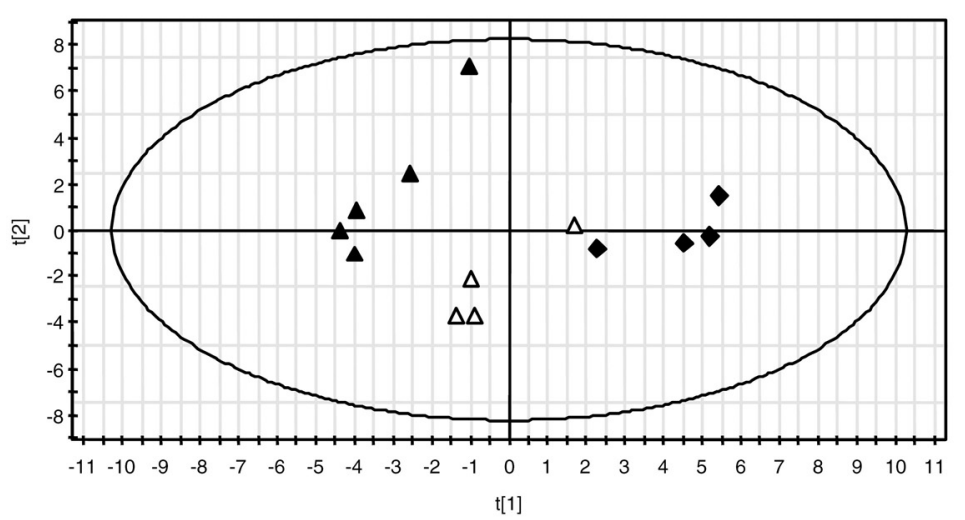

(b)

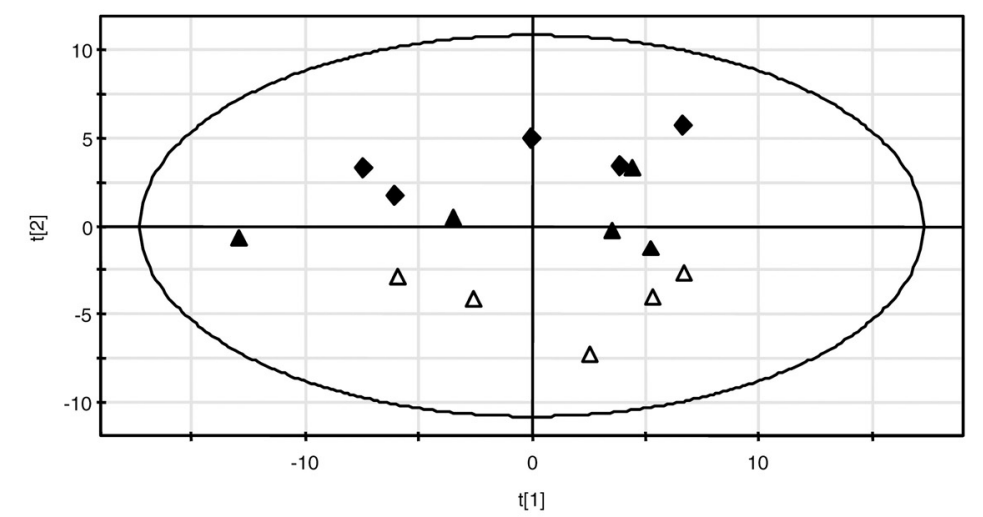

(c)

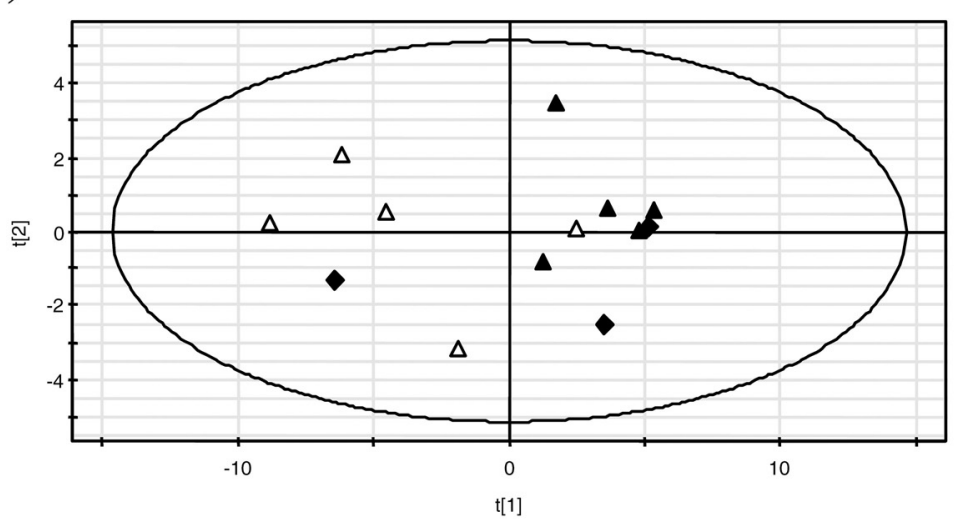

Fig. 4. Unsupervised PCA scores plots of reproductive organs excised from rats at $24 \mathrm{hr}$ after EGME administration. PCA scores plots for the first 2 principal components $(t[1], t[2])$ of testes (a), caput region of the epididymides (b), and cauda region of the epididymides (c), showing clustering according to the damage induced by EGME on tissues. PCA scores were calculated on the basis of Hr-MAS ${ }^{1} \mathrm{H}-\mathrm{NMR}$ CPMG spectra. The closed diamonds and open and closed triangles represent the control, and low- and high-dose EGME groups, respectively. The confidence interval is defined by the Hotelling's T2 ellipse (95\% confidence interval). Several observations were omitted in PCA scores plots of testes (a) and cauda epididymides (c), because the observations were plotted outside the confidence ellipse and considered to be outliers. 
Metabonomic investigation of testicular toxicity induced by EGME.

The changes in endogenous metabolites in the testes and caput epididymis are summarized in Table 3. They were disclosed by subsequent PLS-DA analysis. The levels of 11 endogenous metabolites in the testes and 1 in the caput epididymides showed a decrease or increase after the administration of EGME. The pre- dominant changes were an increase of lactate, acetate and amino acids, and a decrease of creatine, glutathione (GSH) and phosphocholine. The level of lipid decreased in the caput region of the epididymis.

(a)

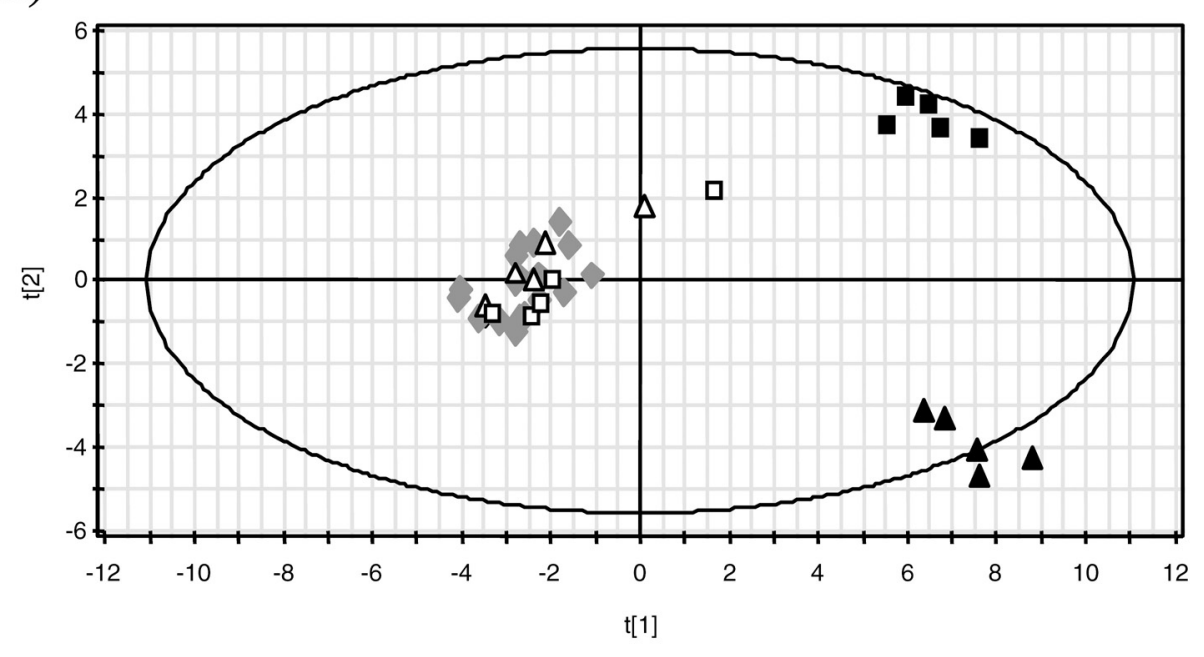

(b)

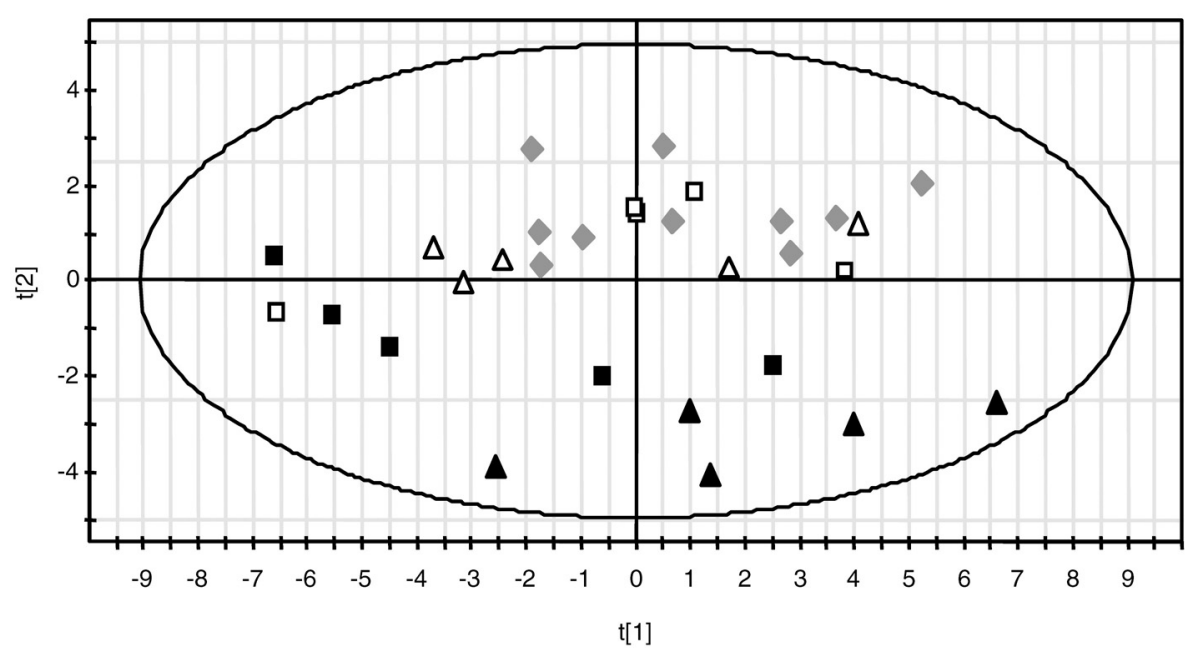

Fig. 5. Unsupervised PCA plots of scores for the first 2 principal components ( $t[1], t[2])$ based on ${ }^{1} \mathrm{H}-\mathrm{NMR}$ spectra of urine (a) and plasma (b) of rats administered EGME. The symbols, which are colored with gray, white and black, represent pre-dose (or control), and low and high dose of EGME, respectively. As for the PCA scores plot of urine (a), the triangles and squares indicate 0 to $8 \mathrm{hr}$ and 8 to $24 \mathrm{hr}$ collection periods, respectively. Regarding the PCA scores plot of plasma (b), the triangles and squares indicate the $6 \mathrm{hr}$ and $24 \mathrm{hr}$ time points, respectively. 


\section{T. YAMAMOTO et al.}

\section{Metabonomic analysis of biofluids}

The ${ }^{1} \mathrm{H}-\mathrm{NMR}$ spectra of urine and plasma obtained at two time points and two dose levels exhibited an altered biochemical composition. The PCA scores plot of urine ${ }^{1} \mathrm{H}$-NMR spectra showed that the three different clusters, non-affected (pre-dose and low-dose) and affected (high-dose), were clearly organized (Fig. 5a). The PCA scores of plasma at control and high-dose were relatively separated (Fig. 5b).

Table 3 also shows the affected endogenous metabolites in urine and plasma as well as in reproductive organs. In total, 8 metabolites were affected in urine and 5 in plasma. The major biochemical changes identified in urine were a decrease in the levels of 2oxoglutarate, citrate, hippurate and succinate, which are intermediates in the tricarboxylic acid (TCA) cycle. Moreover, it was found that ketone-bodies, acetoacetate and $\alpha$-hydroxyisovalerate, were increased in urine. In plasma, an increase in alanine and lactate, a decrease in $\alpha$-glucose, $\beta$-hydroxybutyrate and glycine were detected.

\section{DISCUSSION}

"Solid-state" Hr-MAS ${ }^{1} \mathrm{H}-\mathrm{NMR}$ spectroscopy enables the assessment of tissues in the intact ex vivo state, and also the investigation of the content of endogenous metabolites in the cells. The use of $\mathrm{Hr}-$ MAS ${ }^{1} \mathrm{H}-\mathrm{NMR}$ to evaluate reproductive organs was first introduced by Griffin et al. in 2000. They performed a Hr-MAS ${ }^{1} \mathrm{H}-\mathrm{NMR}$ analysis of testes and then catalogued the major metabolites they found by peak assignment. Here we report the first $\mathrm{Hr}-\mathrm{MAS}{ }^{1} \mathrm{H}-\mathrm{NMR}$ spectra of rat epididymides (both caput and cauda regions) as well as testis, and their usefulness to evaluate testicular toxicity induced by a male reproductive toxicant. The testicular spectrum shown in Fig. 2A was identical to previously reported spectra. It was known that the lipid content of epididymal spermatozoa of rats changes along the epididymis (Adams and Johnson, 1977). Lipid changes occur during the epididymal transit of spermatozoa as they mature, indicating that alterations in membrane fluidity by lipid remodeling plays an important role in determining the structure and functions of the sperm membrane (Rana et al., 1991; Aveldano et al., 1992). According to our finding from the epididymal Hr-MAS ${ }^{1} \mathrm{H}-\mathrm{NMR}$ shown in Figs. $2 \mathrm{~B}$ and $2 \mathrm{C}$, the lipid content in the caput epididymis was higher than that in the cauda, which was consistent with data from previous reports.

In the metabonomic analyses of reproductive organs, the score plots from PCA and PLS-DA analyses of testicular Hr-MAS ${ }^{1} \mathrm{H}-\mathrm{NMR}$ spectra demonstrated that each treatment group formed different clus-

Table 3. Summary of endogenous metabolites detected by ${ }^{1} \mathrm{H}-\mathrm{NMR}$ metabonomics that were induced or suppressed by EGME in reproductive organs and biofluids of male rats.

\begin{tabular}{|c|c|c|c|}
\hline & & \multicolumn{2}{|c|}{ Affected Endogenous Metabolites } \\
\hline & & Increase & Decrease \\
\hline \multirow[t]{8}{*}{ Tissues } & Testis & - acetate (high) & - creatine (high) \\
\hline & & - alanine (low < high) & - phosphatidylcholine (high) \\
\hline & & - glutamate (high) & - phosphocholine (low=high) \\
\hline & & - isoleucine (high) & - glutathione (low=high) \\
\hline & & - lactate (low<high) & \\
\hline & & - leucine (high) & \\
\hline & & - lysine (low<high) & \\
\hline & Epididymis (caput region) & & - lipid (low=high) \\
\hline \multirow[t]{7}{*}{ Biofluids } & Urine & - acetoacetate (high- $8<$ high-24) & - 2-oxoglutarate (high-8<high-24) \\
\hline & & - $\alpha$-glucose (high-8>high-24) & - citrate (high- $8<$ high-24) \\
\hline & & - $\alpha$-hydroxyisovalerate (high-8=high-24) & - hippurate (high-8>high-24) \\
\hline & & - $\beta$-hydroxybutyrate (high-8>high-24) & - succinate (high) \\
\hline & Plasma & - $\alpha$-glucose (high-6=high-24) & - alanine (high-6=high-24) \\
\hline & & - $\beta$-hydroxybutyrate (high-24) & - lactate (high-6=high-24) \\
\hline & & - glycine (high-6>high-24) & \\
\hline
\end{tabular}

Variations compared to control samples.

Treatment and time point at which the changes in the level of endogenous metabolites were detected are shown in parentheses, namely, (high-8) means that the change was observed at $8 \mathrm{hr}$ after the administration of a high dose of EGME. 
Metabonomic investigation of testicular toxicity induced by EGME.

ters in scores plots (Fig. 4a), indicating that EGME was highly affected to endogenous metabolites. In the testes, the major alterations were an increase in lactate and decreases in creatine and GSH. In the testes and the caput epididymides, the components of the sperm membrane, such as phosphocholine, phosphatidylcholine and lipid, were also mainly affected.

Testicular lactate increased and plasma lactate decreased in the present study. Lactate is produced via pyruvate metabolism from glucose subsequent to cytosolic glycolysis, which occurs in Sertoli cells (Robinson and Fritz, 1981; Bajpai et al., 1998). It is considered that testicular organs need great energy to continuously maintain spermatogenesis. It was reported that intracellular infusion of lactate improved spermatogenesis by preventing loss of germ cells in the rat cryptorchid testes (Courtens and Ploen, 1999). Erkkila et al. (2002) also demonstrated that lactate effectively inhibited apoptosis of testicular germ cells in a dose-dependent manner. As described above, lactate is an essential substrate in spermatogenesis for the regulation of survival of pachytene spermatocytes (Jutte et al., 1981, 1982). Lactate seems to be supplied in the seminiferous tubules from two main sources, an endogenous (intracellular) and an exogenous (extracellular) one (Brauchi et al., 2005). One of these sources (routes) is the supply from Sertoli cells, and this is mediated by the L-lactate transport system with monocarboxylate transporter 4 (MCT4) in spermatogenic germ cells. On another route, lactate is also uptaken by pachytene spermatocytes from blood using MCT1. EGME is a specific toxicant to spermatocytes, but methoxyacetic acid (MAA), which is the major metabolite of EGME, also inhibits lactate production in Sertoli cells in vitro (Beattie et al., 1984). Under normal conditions, the intracellular concentration of lactate is regulated by hormonal control and supply. However, this balance is perturbed when the testes are toxicologically damaged. The alterations of lactate content detected in the present study might be attributed to a perturbation of this balance due to spermatocytes degeneration induced by EGME.

In the testes, creatine content decreased in the high-dose group. As shown by testicular Hr-MAS ${ }^{1} \mathrm{H}$ NMR spectroscopy, testicular tissue has high concentrations of creatine. In fact, creatine concentration in rat testes and seminal fluid is significantly higher than in blood (Lee et al., 1988). The finding indicated that sperm cells require a high concentration of creatine to maintain their viability and function. Timbrell and coworkers reported that creatine in urine and plasma was associated with testicular damage induced by EGME, MAA, cadmium, di-n-pentyl phthalate (DPP), and 1,3dinitrobenzene (1,3-DNB) (Rawcliffe et al., 1989; Gray et al., 1990; Moore et al., 1992; Timbrell, 2000). They concluded that creatine might serve as a useful non-invasive biomarker of male reproductive dysfunctions. In the present metabonomic study, however, urinary and plasmatic creatine did not change. This was probably because the spermatocytes degeneration induced by EGME was relatively mild, as demonstrated by conventional toxicity data showing no changes in reproductive organs weight and minor histopathological findings. According to the investigations conducted by Timbrell et al., the elevation of creatine in urine was likely to be caused by severe testicular damage. Therefore, our results are consistent with previous findings.

As another considerable mechanism of testicular toxicity, the effect of oxidative stress on testicular toxicity should be considered. The significant reduction in GSH level in mouse or rat testes has been previously documented (Shen and Sangiah, 1995; Turk et al., 2007). In the present study, testicular GSH also decreased after the administration of EGME. Consequently, oxidative stress was thought to contribute to the testicular toxicity induced by chemicals. In addition, alterations in the expression of oxidative stressrelated genes and proteins would further support this mechanism. We have already documented that the expression of antioxidant protein 2 and glutathione $S$ transferase at both the protein and transcription levels is altered by reproductive toxicants (Fukushima et al., 2005; Yamamoto et al., 2005).

The urine metabonomic analysis showed decreased excretions of the TCA cycle intermediates, 2-oxoglutarate, citrate and succinate. Additionally, the ketone-bodies, acetoacetate and $\beta$-hydroxybutyrate, were increased in urine. Normally, ketone-bodies are transported from the liver to other tissues including reproductive organs, where they can be reconverted to acetyl-CoA to produce energy. An impairment of the TCA cycle leads to increased release of ketone-bodies from liver for use as fuel in other tissues. When evaluating metabonomic changes in biofluids such as plasma and urine, we should pay much attention to the specificity of damaged organs in the body. Indeed, the alterations of TCA cycle intermediates in the present study might offer a general decrease of energy metabolism, which was supported by the decreased body weight in high-dose $24 \mathrm{hr}$ group. In addition, we also attributed the decrease in urinary TCA cycle intermedi- 
ates observed in this study to the suppression of TCA cycle in the testes, and the increase of ketone-bodies in urine and plasma might reflect that effect of EGME. Elevations of amino acids in the testes suggested that the TCA cycle was likely to be suppressed in testicular organs. As for the relevance of TCA cycle suppression in testicular toxicity, it was reported that spermatocytes and spermatids died when the TCA cycle was inhibited (Jutte et al., 1982).

Based on the present testicular metabonomic analysis, we propose that testicular toxicity induced by EGME resulted from either perturbation of the energy supply processes, suppression of the TCA cycle, or oxidative stress, or all of these factors. In summary, integration of the analyses of intact tissues and biofluids using ${ }^{1} \mathrm{H}-\mathrm{NMR}$ provides a more detailed knowledge of in vivo molecular events. Hr-MAS ${ }^{1} \mathrm{H}-\mathrm{NMR}$ spectroscopy of intact tissues is useful in toxicological investigations because the spectra are relatively easy to obtain within a few minutes, and measurements are conducted in a high throughput manner. Using HrMAS ${ }^{1} \mathrm{H}-\mathrm{NMR}$, it is possible to investigate whether a target organ is normal or damaged, before histopathological changes can be detected.

\section{ACKNOWLEDGMENT}

The authors are grateful to Ms. Yukiko Sasayama, Dr. Rie Kikkawa and Dr. Tamio Fukushima, Pfizer Global Research \& Development, Nagoya Laboratories, for the conventional toxicological examinations, and to Mr. Shinichi Sakemi, Pfizer Global Research \& Development, Nagoya Laboratories, for technical support regarding NMR measurements. The authors are also grateful to Dr. Hiroshi Yamada, Pfizer Global Research \& Development, Nagoya Laboratories, for his helpful advices.

\section{REFERENCES}

Adams, C.S. and Johnson, A.D. (1977): The lipid content of epididymal spermatozoa of Rattus Norvegicus. Comp. Biochem. Physiol., 58B, 409411.

Anderson, D., Brinkworth, M.H., Jenkinson, P.C., Clode, S.A., Creasy, D.M. and Gangolli, S.D. (1987): Effects of ethylene glycol monomethyl ether on spermatogenesis, dominant lethality, and $F_{1}$ abnormalities in the rat and the mouse after treatment of $\mathrm{F}_{0}$ males. Teratog.Carcinog. Mutagen., 7, 141-158.
Aveldano, M.I., Rotstein, N.P. and Vermouth, N.T. (1992): Lipid remodeling during epididymal maturation of rat spermatozoa. Biochem. J., 283, 235-241.

Azmi, J., Connelly, J., Holmes, E., Nicholson, J.K., Shore, R.F. and Griffin, J.L. (2005): Characterization of the biochemical effects of 1 nitronaphthalene in rats using global metabolic profiling by NMR spectroscopy and pattern recognition. Biomarker, 10, 401-416.

Bajpai, M., Gupta, G. and Setty, B.S. (1998): Changes in carbohydrate metabolism of testicular germ cells during meiosis in the rat. Eur. J. Endocrinol., 138, 322-327.

Beattie, P.J., Welsh, M.J. and Brabec, M.J. (1984): The effect of 2-methoxyethanol and methoxyacetic acid on Sertoli cell lactate production and protein synthesis in vitro. Toxicol. Appl. Pharmacol., 76, 56-61.

Brauchi, S., Rauch, M.C., Alfaro, I.E., Cea, C., Concha, I.I., Benos, D.J. and Reyes, J.G. (2005): Kinetics, molecular basis, and differentiation of L-lactate transport in spermatogenic cells. Am. J. Physiol. Cell. Physiol., 288, C523C534.

Chapin, R.E. and Lamb, J.C.IV (1984): Effects of ethylene glycol monomethyl ether on various parameters of testicular function in the F344 rat. Environ. Health Perspect., 57, 219-224.

Chapin, R.E., Dutton, S.L., Ross, M.D., Sumrell, B.M. and Lamb, J.C.IV (1984): The effects of ethylene glycol monomethyl ether on testicular histology in F344 rats. J. Androl., 5, 369-380.

Cheng, L.L., Becerra, M.L., Hale, I., Tracy, A., Lackner, A. and Gonzalez, R.G. (1997): Quantitative neuropathology by high resolution magic angle spinning proton magnetic resonance spectroscopy. Proc. Natl. Acad. Sci. USA., 94, 64086413.

Coen, M., Lenz, E.M., Nicholson, J.K., Wilson, I.D., Pognan, F. and Lindon, C. (2003): An integrated metabonomic investigation of acetaminophen toxicity in the mouse using NMR spectroscopy. Chem. Res. Toxicol., 16, 295-303.

Courtens, J.L. and Ploen, L. (1999): Improvement of spermatogenesis in adult cryptorchid rat testis by intratesticular infusion of lactate. Biol. Reprod., 61, 154-161.

Erkkila, K., Aito, H., Aalto, K., Pentikainen, V. and Dunkel, L. (2002): Lactate inhibits germ cell apoptosis in the human testis. Mol. Human 
Metabonomic investigation of testicular toxicity induced by EGME.

Reprod., 8, 109-117.

Foster, P.M.D., Creasy, D.M., Foster, J.R. and Gray, T.J.B. (1984): Testicular toxicity produced by ethylene glycol monomethyl and monoethyl ethers in the rat. Environ. Health Perspect., 57, 207-217.

Foster, P.M.D., Creasy, D.M., Foster, J.R., Thomas, L.V., Cook, M.W. and Gangolli, S.D. (1983): Testicular toxicity of ethylene glycol monomethyl and monoethyl ethers in the rat. Toxicol. Appl. Pharmacol., 69, 385-399.

Fukushima, T., Yamamoto, T., Kikkawa, R., Hamada, Y., Komiyama, M., Mori, C. and Horii, I. (2005): Effects of male reproductive toxicants on gene expression in rat testes. J. Toxicol. Sci., 30, 195-206.

Gad, S.C. and Weil, C.S. (1994): Statistics for toxicologists. In Principles and Methods of Toxicology (Hayes, A.W., ed.), pp. 221-274, Raven Press, New York.

Garrod, S., Humpfer, E., Spraul, M., Connor, S.C., Polley, S., Connelly, J., Lindon, J.C., Nicholson, J.K. and Holmes, E. (1999): High-resolution magic angle spinning ${ }^{1} \mathrm{H}-\mathrm{NMR}$ spectroscopic studies on intact rat renal cortex and medulla. Magn. Reson. Med., 41, 1108-1118.

Garrod, S., Humpher, E., Connor, S.C., Connelly, J.C., Spraul, M., Nicholson, J.K. and Holmes, E. (2001): High-resolution ${ }^{1} \mathrm{H}-\mathrm{NMR}$ and magic angle spinning NMR spectroscopic investigation of the biochemical effects of 2-bromoethanamine in intact renal and hepatic tissue. Magn. Reson. Med., 45, 781-790.

Gray, J., Nicholson, J.K., Creasy, D.M. and Timbrell, J.A. (1990): Studies on the relationship between acute testicular damage and urinary and plasma creatine concentration. Arch. Toxicol., 64, 443450.

Griffin, J.L., Troke, J., Walker, L.A., Shore, R.F., Lindon, J.C. and Nicholson, J.K. (2000): The biochemical profile of rat testicular tissue as measured by magic angle spinning ${ }^{1} \mathrm{H}-\mathrm{NMR}$ spectroscopy. FEBS Lett., 486, 225-229.

Jutte, N.H.P.M., Grootegoed, J.A., Rommerts, F.F.G. and van der Molen, H.J. (1981): Exogenous lactate is essential for metabolic activities in isolated rat spermatocytes and spermatids. J. Reprod. Fertil., 62, 399-405.

Jutte, N.H.P.M., Jansen, R., Grootegoed, J.A., Rommerts, F.F.G., Clausen, O.P.F. and van der Molen, H.J. (1982): Regulation of survival of rat pachytene spermatocytes by lactate supply from Sertoli cells. J. Reprod. Fertil., 65, 431-438.

Lee, H.J., Fillers, W.S. and Iyengar, M.R. (1988): Phosphocreatine, an intracellular high-energy compound, is found in the extracellular fluid of the seminal vesicles in mice and rats. Proc. Natl. Acad. Sci. USA., 85, 7265-7269.

Lelliott, C.J., Lopez, M., Curtis, R.K., Parker, N., Laudes, M., Yeo, G., Jimenez-Linan, M., Grosse, J., Saha, A.K., Wiggins, D., Hauton, D., Brand, M.D., O'Rahilly, S., Griffin, J.L., Gibbons, G.F. and Vidal-Puig, A. (2005): Transcript and metabolic analysis of the effects of tamoxifen in rat liver reveals inhibition of fatty acid synthesis in the presence of hepatic steatosis. FASEB J., 19, 1108-1119.

Lindon, J.C., Nicholson, J.K., Holmes, E. and Everett, J.R. (2000): Metabonomics: Metabolic processes studies by NMR spectroscopy of biofluids. Concepts Magn. Reson., 12, 289-300.

Martin, F.P.J., Wang, Y., Sprenger, N., Holmes, E., Lindon, J.C., Kochhar, S. and Nicholson, J.K. (2007): Effects of probiotic Lactobacillus Paracasei treatment on the host gut tissue metabolic profiles probed via magic-angle-spinning NMR spectroscopy. J. Proteome Res., 6, 1471-1481.

Moore, N.P., Creasy, D.M., Gray, T.J.B. and Timbrell, J.A. (1992): Urinary creatine profiles after administration of cell-specific testicular toxicants to the rat. Arch. Toxicol., 66, 435-442.

Rana, A.P.J., Majumder, G.C., Mirsa, S. and Ghosh, A. (1991): Lipid changes of goat sperm plasma membrane during epididymal maturation. Biochim. Biophys. Acta., 1061, 185-196.

Rawcliffe, L., Creasy, D. and Timbrell, J.A. (1989): Urinary creatine as a possible marker for testicular damage: Studies with the testicular toxic compound 2-methoxyethanol. Reprod. Toxicol., 3, 269-274.

Robinson, R. and Fritz, I.B. (1981): Metabolism of glucose by Sertoli cells in culture. Biol. Reprod., 24, 1032-1041.

Schenetti, L., Mucci, A., Parenti, F., Cagnoli, R., Righi, V., Tosi, M.R. and Tugnoli, V. (2006): HR-MAS NMR spectroscopy in the characterization of human tissues: Application to healthy gastric mucosa. Concepts Magn. Reson., 28A, 430-443.

Shen, Y. and Sangiah, S. (1995): $\mathrm{Na}^{+}, \mathrm{K}^{+}$-ATPase, glutathione, and hydroxyl free radicals in cadmium chloride-induced testicular toxicity in mice. 
Arch. Environ. Contam. Toxicol., 29, 174-179.

Syed, V. and Hecht, N.B. (1998): Rat pachytene spermatocytes down-regulate a polo-like kinase and up-regulate a thiol-specific antioxidant protein, whereas Sertoli cells down-regulate a phosphodiesterase and up-regulate an oxidative stress protein after exposure to methoxyethanol and methoxyacetic acid. Endocrinol., 139, 35033511 .

Tessem, M.B., Bathen, T.F., Lofgren, S., Saether, O., Mody, V., Meyer, L., Dong, X., Soderberg, P.G. and Midelfart, A. (2006): Biological response in various compartments of the rat lens after in vivo exposure to UVR-B analyzed by HR-MAS ${ }^{1} \mathrm{H}-\mathrm{NMR}$ spectroscopy. Invest. Ophthalmol. Vis. Sci., 47, 5404-5411.

Timbrell, J.A. (2000): Urinary creatine as a biochemical marker of chemical induced testicular damage. Arh. Hig. Rada. Toksikol., 51, 295-303.

Turk, G., Atessahin, A., Sonmez, M., Yuce, A. and Ceribasi, A.O. (2007): Lycopene protects against cyclosporine A-induced testicular toxic- ity in rats. Theriogenology, 67, 778-785.

Yamamoto, T., Fukushima, T., Kikkawa, R., Yamada, H. and Horii, I. (2005): Protein expression analysis of rat testes induced testicular toxicity with several reproductive toxicants. J. Toxicol. Sci., 30, 111-126.

Wang, W. and Chapin, R.E. (2000): Differential gene expression detected by suppression subtractive hybridization in the ethylene glycol monomethyl ether-induced testicular lesion. Toxicol. Sci., 56, 165-174.

Waters, N.J., Holmes, E., Williams, A., Waterfield, C.J., Farrant, R.D. and Nicholson, J.K. (2001): NMR and pattern recognition studies on the time-related metabolic effects of $\alpha$-naphthylisothiocyanate on liver, urine, and plasma in the rat: An investigative metabonomic approach. Chem.Res. Toxicol., 14, 1401-1412.

Wiley, F.H., Hueper, W.C. and von Oettingen, W.F. (1936): The toxicity and potential dangers of ethylene glycol. J. Ind. Hyg. Toxicol., 18, 123126. 